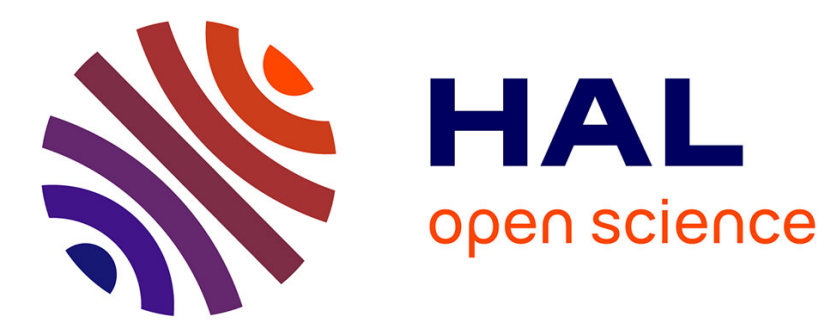

\title{
Los límites de la escritura epidíctica: la poesía jocoseria de José Pérez de Montoro
}

\author{
Alain Begue
}

\section{To cite this version:}

Alain Begue. Los límites de la escritura epidíctica: la poesía jocoseria de José Pérez de Montoro.

Criticón, 2007, 100, pp.143 - 166. 10.4000/criticon.9399 . hal-02522950

\section{HAL Id: hal-02522950 \\ https://hal.science/hal-02522950}

Submitted on 28 Mar 2020

HAL is a multi-disciplinary open access archive for the deposit and dissemination of scientific research documents, whether they are published or not. The documents may come from teaching and research institutions in France or abroad, or from public or private research centers.
L'archive ouverte pluridisciplinaire HAL, est destinée au dépôt et à la diffusion de documents scientifiques de niveau recherche, publiés ou non, émanant des établissements d'enseignement et de recherche français ou étrangers, des laboratoires publics ou privés. 


\title{
Los límites de la escritura epidíctica: la poesía jocoseria de José Pérez de Montoro
}

\author{
Alain Bègue \\ FoReLL B2, Université de Poitiers
}

En una sociedad donde el individuo se definía en función de la distancia que le separaba de las esferas de prestigio y de poder - cuyo centro era el monarca y sus familiares, a los que seguían, según un orden decreciente de importancia, la alta nobleza y los altos cargos seculares de la administración real-, la poesía podía convertirse en un medio eficaz para medrar en ella, para obtener algún reconocimiento, privado o público, y, en la mayoría de los casos, financiero. Esto era tanto más verdadero cuanto que la clase dominante daba señas de un cierto interés por las prácticas literarias, bien dedicándose personalmente a la escritura, como en el caso de Felipe IV, bien concediendo una protección a ciertos poetas o incluso favoreciendo manifestaciones públicas como fue el caso de las academias literarias. Así, pues, dentro de la polifonía poética barroca, y de esa fragmentación de la enunciación poética de la época, la voz del poeta cortesano y áulico era sin duda alguna una de las más importantes. Inspirados por su propia musa o sometidos a la rigidez de un ejercicio estilístico y retórico impuesto, los escritores estuvieron siempre dispuestos a ensalzar a sus superiores sociales, como manifiestan los cuantiosos géneros que constituyen la elocuencia de la pompa, que se despliega en los panegíricos, genetlíacos, epitalamios, epicedios y otras manifestaciones oratorias que constituían una parte no despreciable de su producción literaria. Cuantos poetas albergó el siglo XVII, e incluso los considerados hoy en día como mejores, fueron concernidos, "obligados con su pluma a preservar o elevar el estatuto de los sistemas de poder de la época» ${ }^{1}$. Y José Pérez de Montoro (Játiva, 1627-Cádiz, 1694), uno de los autores más afamados de las últimas décadas del siglo xvir y de principios del xviII, fue uno más de estos autores polígrafos que pusieron su pluma al servicio de la clase dirigente, nobiliaria o no. La poesía epidíctica del autor setabense, que refleja «el gusto

${ }^{1}$ Jauralde, 1999, p. 43. 
barroco por la profusión de hipérboles ${ }^{2}$, pertenece en efecto casi enteramente a una poesía de Corte.

Ahora bien, seis de las composiciones laudatorias de Pérez de Montoro fueron publicadas en su vida con un título que las presentaba bien como jocoserias, bien como serijocosas ${ }^{3}$. Fueron escritas, de igual modo que sus obras serias, con motivo de una res certa, sobre la que debe apoyarse cualquier elogio, según Quintiliano ${ }^{4}$ : un nacimiento ${ }^{5}$, un cumpleaños ${ }^{6}$, una curación ${ }^{7}$, una boda ${ }^{8}$ o una entrada real. A esta última categoría perteneció el romance "Invicto segundo Carlos", cuyo título en las obras póstumas del autor reza: Al rey, nuestro señor, en la deseada feliz noticia de hallarse ya la reina nuestra señora en España, romance jocoserio [que le pone] a los reales pies de su Majestad don Joseph Pérez de Montoro'. La propia versión impresa de la composición, publicada probablemente en Valencia el mismo año de la llegada de Mariana de Neoburgo, presentaba explícitamente el poema como "romance jocoserio» ${ }^{10}$. Estos rótulos, que hacen hincapié en un estilo seguramente reconocido por los receptores de la época, no dejan de resultar llamativos y su detenido estudio arrojará luz sobre la escritura epidíctica en particular y poética en general de entre siglos.

\section{EL ESTILO JOCOSERIO A LA LUZ DE LA OBRA DE PEREZ DE MONTORO}

En 1645, Manuel Antonio de Vargas, editor de la Jocoseria, subrayaba, en su dedicatoria al caballero napolitano Mario Mastrillo Beltrán, el doble propósito cómico y edificante de los entremeses de su amigo y autor de teatro breve Luis Quiñones de Benavente $^{11}$. Ya en 1635, Salas Barbadillo había declarado que las musas del

${ }^{2}$ Egido, 1990, p. 42.

${ }^{3}$ No haremos, en nuestro estudio, ninguna distinción entre ambos términos, como lo hiciera Jean-Pierre Étienvre en un artículo de imprescindible lectura para una visión teórica, ideológica y diacrónica de lo jocoserio (Étienvre, 2004).

${ }^{4}$ Quintilien, Institution oratoire, VII, 4, 3.

${ }^{5}$ El romance «Gran Señor, excelso Duque» (Obras posthumas lyricas —en adelante OP-, I, pp. 134138), dirigido al duque de Veragua, escrito en los años 1680 con el propósito de celebrar el nacimiento de la hija de éste, Josefa Micaela de Portugal y Ayala.

${ }^{6} \mathrm{El}$ romance "iOh, qué ufana está la rosa" dedicado, en nombre de Álvaro Colón de Portugal, segundón del duque de Veragua, a la Reina madre, iba acompañado de otro, cuyo primer verso era «Si aun el dar a las deidades" (OP, 1 , p. 171-173) y que fue escrito en las mismas circunstancias que el primero, esto es, con motivo de la academia literaria celebrada en Cádiz el 22 de diciembre de 1672 para el cumpleaños de Mariana de Austria.

${ }^{7}$ Los romances «Señor, de vuestro accidente» (OP, I, pp. 74-78) y "Si el brindis a dos saludes» (OP, I, pp. 78-84) expresan la alegría del autor ante la curación de Carlos II.

${ }^{8}$ En su poema epidíctico más largo, el romance de 640 versos "Ordéname Useñoría" (OP, I, pp. 324340), encargado por el marqués de la Mina, Pérez de Montoro celebra con humor la boda del conde de Niebla, primogénito y, por consiguiente, sucesor del duque de Medina-Sidonia, celebrada en Sevilla probablemente en 1687.

${ }^{9} \mathrm{OP}$, pp. 67-72.

${ }^{10}$ AL REY I NUESTRO SEÑOR, I EN LA DESEADA | FELIZ NOTICIA | de hallarse ya la Reyna | nuestra Señora en I España. I ROMANCE XOCOSERIO. I PONELE A LOS REALES PIES DE I su Magestad. I DON IOSEPH PEREZ I de Montoro (BNM: VE/194-42).

${ }^{11}$ "A don Mario Mastrillo Beltrán, residente de la serenísima señora archiduquesa de Austria, Claudia de Médicis, en la Corte de España», en Quiñones de Benavente, Entremeses completos I. Jocoseria, pp. 115-119 
dramaturgo no eran «desacatadas ni desatacadas» ${ }^{12}$. Pero, si la finalidad de enseñanza y de provecho moral se justificaba, en el subtítulo dado a la compilación (Joco seria. Burlas veras, o reprehensión moral y festiva de los desórdenes públicos), por el contexto de hostilidad al teatro en aquellos años, la verdad es que las obras dramáticas breves de Quiñones de Benavente distaban de obedecer al principal criterio editorial, pese a la indiscutible autocensura a la que se sometió su autor. La función lúdica acababa por invadir, quizá contra la voluntad del dramaturgo, el conjunto de la colección.

Algunos años más tarde, González de Salas, editor de las obras poéticas de Quevedo, precisaba también la finalidad satírica moral y edificante de las composiciones que había llamado «jocoserias» en su explicación del contenido de la Musa VI de El Parnaso Español (1648):

Canta poesías jocoserias, que llamó burlescas el autor, esto es, descripciones graciosas, sucesos de donaire y censuras satíricas de culpables costumbres, cuyo estilo es todo templado de burlas $\mathrm{y}$ veras.

Así, para Vargas y González de Salas, el estilo jocoserio se caracterizaba por la mezcla de burlas y de elementos serios destinados a censurar los vicios culpables de la sociedad, un estilo, pues, muy cercano al satírico. Pero es el caso que, en las composiciones poéticas de Pérez de Montoro presentadas como jocoserias o serijocosas, tampoco aparece el imprescindible propósito edificante. Conviene, por lo tanto, interrogarse sobre las características que esconde el epíteto jocoserio atribuido a algunas de las obras de nuestro poeta.

Marcos Lanuza de Arellano, conde de Clavijo, gentilhombre de boca de Carlos II, nos brinda algunos indicios en su romance "Vayan, señor, vayan fuera", inspirado en la composición «Si el brindis a dos saludes» escrita por Pérez de Montoro para celebrar el saludable restablecimiento del rey Carlos II y de su esposa, la reina María Luisa de Orleáns. La larga introducción del poema compuesto por el conde de Clavijo se presenta a la vez como un elogio y como una dura crítica del estilo al que había acudido nuestro poeta valenciano:

\author{
Vayan, señor, vayan fuera \\ Castalia, Aganipe y Pindo, \\ alhajas que sólo sirven \\ de lo que hasta aquí han servido. \\ No haya invocación al templo 5 \\ de aquél que, en Delfos fingido, \\ tuvo entre los mentecatos \\ plausibles los sacrificios. \\ No del caballo de Apolo \\ se haga memoria, aunque miro

(p. 116): «[...] añadiendo a esta novedad perfección tan suma, que si no excedió a los antiguos, desespera de su imitación a los venideros, al mezclar lo útil de advertimientos morales con lo dulce de invenciones graciosísimas, sirviendo estas sales tanto para preservar la corrupción de las costumbres que reprehendían, cuanto para sazonar el gusto de quien deleitaban".

${ }^{12}$ Citado en la introducción de Quiñones de Benavente, Entremeses completos I. Jocoseria, p. 47. 
que sin moverse ha causado

a los poetas gran ruido.

Parece que jocoserio

se me introduce el estilo,

y que sin ser yo Montoro,

tan no fácil senda piso.

¿Qué será? ¿Si es que el ingenio

me lleva por el camino

de lo burlesco, y se aparta

del más discreto camino?

No, porque mi natural

siempre me lleva advertido

al objeto de lo heroico,

donde es seguro el camino.

¿No es mejor esto, que no

conceptos del baratillo

sobre si Fermín es tonto,

sobre si Lira es propicio?

$¿$ No es mejor el dulce grave

métrico acordado ritmo

de las cítaras, que no

de las campanas el ruido?

No hay cosa como lo grande, en donde siempre han servido

la gran razón del pensarlo, de razón para escribirlo.

Además, que los ingenios heroicos, cuando han querido han hecho sus versos flautas, y también sus coplas pitos. (OP, I, pp. 165-166)

En este poema, Clavijo empieza presentándose - y lo confirmará más adelante en los versos 13-16 - como un fiel imitador de la escritura jocoseria de Pérez de Montoro. Esta escritura aparece como paródica, en la medida que procede a una degradación estilística del topos convencional de la petición de inspiración divina. El rechazo de las diferentes fuentes míticas de la inspiración -Castalia y Aganipe-, de los lugares de reunión míticos de las Musas —el Pindo y Delfos-, del noble Pegaso - vulgarmente presentado como el sencillo "caballo de Apolo"-, así como la caracterización peyorativa del texto, mediante la metáfora negativa («alhajas que sólo sirven / de lo que hasta aquí han servido"), la adjetivación ("Delfos fingido") o la introducción del estilo llano («mentecatos», "caballo»), participan de la degradación de este tópico de las introducciones poéticas.

A continuación, el escritor aristócrata, en clara ruptura con el movimiento inicial de su composición, parece tomar sus distancias con lo que acaba de escribir y rechazar el estilo jocoserio que designa como característica de la poesía de Montoro, de esa poesía 
que buscaba el juego y el destello estético, el «delectare y el entretenimiento procedente de la habilidad estilística" ${ }^{13}$.

Y es que, para Clavijo, a esa condenable tonalidad burlesca de lo jocoserio debe ser preferido el estilo heroico, hacia el cual le lleva el seguro y "discreto" camino de su espíritu y de su natural "advertido". Los dos caracterizadores así utilizados-discreto y advertido- se oponen textualmente al adjetivo sustantivado "burlesco", y Pérez de Montoro queda definido como un poeta cuya escritura es incapaz de elevarse y cuya inspiración queda limitada a unos objetivos bajos, como son atacarse ferozmente a Fermín de Sarasa y Arce, gentilhombre del duque de Medinaceli y, por ende, adversario del autor setabense, o celebrar la curación de Manuel de Lira, quien, a pesar de ser secretario del Despacho Universal y uno de los diplomáticos más hábiles del reino, no dejaba de ser un simple funcionario.

Una curación celebrada por Montoro en una composición jocoseria en que existía, entre el tema tratado - de naturaleza más bien seria o heroica- y el estilo burlesco empleado por el poeta, una indudable inadecuación o, por decirlo en términos áureos, en que se daba una grave ruptura del decoro. Hasta tal punto que, al denunciar el conde de Clavijo la falta de discernimiento del poeta setabense y su incapacidad para "darle a cada uno su lugar" (no es "discreto", según la definición de Autoridades), nos obliga a contemplar toda la problemática de la poesía jocoseria y a interrogarnos sobre las características contextuales, formales, estructurales y estilísticas de la misma en la obra de José Pérez de Montoro.

\section{EL MARCO CONTEXTUAL}

Los poemas jocoserios señalados como tales en la obra de José Pérez de Montoro son composiciones cuya finalidad cómica se acompaña casi siempre con un propósito grave y/o laudatorio. Así ocurre, por ejemplo, en el romance "A las fiestas vas, romance» y en el soneto "¿Qué estruendo en esos mares se percibe», escritos ambos en alabanza de los soberanos ingleses, el recién difunto Carlos II y su sucesor Jacobo II Estuardo, así como en el romance "Invicto segundo Carlos" que, como veremos más adelante, canta de manera cómica las alabanzas de la reina Mariana de Neoburgo y de Carlos II. Solo el romance «Bueno es, señor, que otra lira» presenta rasgos casi exclusivamente burlescos. Pero dicho poema va precedido por el soneto panegírico jocoserio «La no esperada, la feliz victoria»: éste, que sirve de introducción y se refiere a acontecimientos graves, subraya explícitamente la función de contrapunto burlesco del romance a un poema grave y panegírico anteriormente desarrollado por Diego de Contreras, y, finalmente, adopta un léxico a la par elevado y burlesco. Las mencionadas composiciones de Pérez de Montoro encuentran así su origen en un contexto esencialmente eufórico y laudatorio. $\mathrm{Y}$ buena prueba de ello es el romance "A las fiestas vas, romance», que dedica poco más de la mitad de sus versos a las festividades organizadas a la sazón en Cádiz.

Otro elemento característico de estas obras jocoserias de nuestro autor es que se trata de romances narrativos y descriptivos. El romance "Bueno es, señor, que otra lira» describe la tormenta sufrida por la flota de la Real Armada; el poema «A las fiestas vas,

$$
{ }^{13} \text { Arellano, 2003, p. } 35 .
$$


romance» pinta, en un primer tiempo, la manifestación de duelo de la comunidad inglesa establecida en Cádiz tras la muerte de Carlos II de Inglaterra, para presentar a continuación las festividades organizadas para celebrar la coronación de Jacobo II Estuardo; y el romance "Invicto segundo Carlos» relata la llegada de la reina Mariana de Neoburgo por mar en 1690.

Además, en dos de estos poemas, el destinatario es un aristócrata y, por consiguiente, un superior jerárquico. En este caso, la función primera de los romances jocoserios es divertir a su(s) destinatario(s), lo que conlleva a veces amplificar los procedimientos cómicos hasta la exageración. Los contextos eufóricos de una victoria sobre los elementos, de la llegada de la reina o de festividades varias parecen bastar para justificar la mezcla de burlas y veras, y la ruptura del decoro estilístico que implica lo jocoserio puede, mediante el efecto de sorpresa, participar del placer experimentado por los destinatarios de las composiciones.

Si es así, convendría añadir a las obras poéticas epidícticas jocoserias presentadas como tales el romance «Señor, de vuestro accidente» (OP, I, pp. 74-78), que celebra de manera elogiosa la curación de Carlos II; el romance "Gran señor, excelso duque» (OP, I, pp. 134-138), que da la enhorabuena al duque de Veragua por el nacimiento de su hija Josefa Micaela, hacia 1687, y describe el bautizo; el romance «Si aun el dar a las deidades" (OP, I, pp. 171-173), que conmemora de manera burlesca el cumpleaños de la reina madre Mariana de Austria; y, finalmente, el romance «Ordéname Useñoría» (OP, I, pp. 324-340), que describe las festividades organizadas en Sevilla con motivo de las nupcias del conde de Niebla.

\section{LA JUSTIFICACIÓN DEL ESTILO JOCOSERIO}

Pérez de Montoro se vale, pues, de un contexto eufórico para conferir a algunas de sus obras laudatorias una tonalidad jocoseria. Consciente de la consiguiente ruptura del decoro que supone tal manera de proceder, el poeta trata, en la mayoría de los casos, de justificar el recurso a la escritura jocoseria: así, en el romance «Invicto segundo Carlos", donde, a modo de captatio benevolentiae, el yo lírico explica que la alegría ocasionada por la llegada de la reina no podrá traducirse por medio de una escritura seria sino que será relatada por la locura que guiará la pluma del autor. El socorrido tópico platónico de la alienación de los poetas, del furor divino que inspira momentáneamente a los poetas $^{14}$ sirve entonces de escudo contra las eventuales críticas:

$¿$ Quién se ha de quedar muy grave, meditando en si ha de ser su fatídico embrión norabuena o parabién?

¿Quién ha de sufrir la pluma suspensa con el ten con ten de los riesgos de volar, por no humillarse a correr?

No, señor, no es del contento la seriedad; y ipardiez!, 
que bien me pueden matar, pero yo he de enloquecer.

(OP, I, p. 68, vv. 29-40)

En cuanto al romance «Bueno es, señor, que otra lira", casi enteramente burlesco, el poeta, como vimos, se justifica presentándolo como contrapunto al poema grave de Diego de Contreras que le precede en el impreso ("otra lira») y como en perfecta adecuación con la disformidad del evento:
Bueno es, señor, que otra lira, en consonancias acordes, os divierta, y mi bandurria ni se temple, ni se toque.
Pues no señor, que bien cabe en suceso tan disforme que lo jovial le gorjee, ya que lo serio le entone. (OP, I, p. 208, vv. 1-4, 9-12)

Además, este romance, como ya indicamos, se veía precedido por un soneto panegírico iniciado por Pérez de Montoro en un estilo grave:

La no esperada, la feliz victoria contra los elementos conseguida, oh gran señor, en que de tanta vida el triunfo de salvarse fue la gloria,

por conseguir la eternidad de historia, andar pretende a vuestros pies asida, discurriendo que a vos no se os olvida más de lo que se os va de la memoria.

La doble adjetivación inicial, la caracterización hiperbólica ( "gran», "tanta»), el recurso a sustantivos enfáticos ("victoria", "triunfo", "gloria", "eternidad»), la afectada y tópica expresión de sumisión ( «a vuestros pies asida») confieren a los cuartetos un propósito epidíctico. Pero ya en los tercetos se da un anuncio de lo que va a ser el tono -jocoserio- del romance ofrecido:

Tal cual es el estilo, ha sido justo darle la salsa con que solicito guisaros la tormenta a vuestro gusto;

que así (aunque grave) os la sirvió el conflicto, porque hubo mucho asombro, horror y susto, y del valor el riesgo es apetito. (OP, I, pp. 207-208)

En este caso, pues, los dos estilos opuestos de escritura no se encuentran en el seno de un mismo poema (aunque el romance de Pérez de Montoro presente ciertos elementos 
procedentes del estilo grave) sino en la combinación de varios textos, tal como aparecen ordenados en el impreso.

En el romance «Si el brindis a dos saludes», el autor pide a la reina Mariana de Austria, destinataria del poema, la autorización para escribir en un estilo a la vez loco («mis locos / desatinos») - haciendo de nuevo alusión al tópico del furor divino-y respetuoso («mis locos / desatinos reverentes»), para celebrar la felicidad provocada por la curación de su hijo Carlos II y de su esposa:

Permítame que olvidadas

ya las fatigas, celebren

las glorias estos mis locos

desatinos reverentes.

(OP, I, p. 78, vv. 21-24)

De la misma manera, en el romance "Gran señor, excelso duque", escrito en celebración del nacimiento de Micaela Josefa de Portugal, hija del duque de Veragua, es la alegría del acontecimiento lo que justifica la risa que quiere provocar el poeta:

\author{
Ahora bien, señor, el gusto \\ desmesure la alegría, \\ y ya que he de errarlo, debaos, \\ si no la atención, la risa. \\ Vaya, pues de enhorabuena, \\ y tal cual sea, admitidla, \\ pues sólo será bien dada, \\ si fuere bien recibida. \\ (OP, I, pp. 134-135, vv. 29-36)
}

En el texto siguiente - dice el poeta-, nadie puede mantener la seriedad en un día tan gozoso, realzado ampliamente con la triple sustantivación casi sinonímica «júbilo, alborozo / y alegría»:

Pues, si júbilo, alborozo

y alegría es hoy lo que, porque vino tan despacio, llegó ya tan a placer,

¿Quién se ha de quedar muy grave, meditando en si ha de ser

su fatídico embrión

norabuena o parabién?

(OP, I, p. 67-68, vv. 25-32)

EL TRATAMIENTO DE LA AMBIVALENCIA

Para el tratamiento de los dos aspectos, grave y burlesco, de la escritura jocoseria, Pérez de Montoro no se sometió a una estructura única. La importancia relativa de ambos tipos de discurso varía en función de las composiciones, que pueden ir desde una omnipresencia de lo burlesco hasta una clara diferenciación distributiva de los estilos 
grave y burlesco. Así, el romance "Bueno es, señor, que otra lira" presenta una escritura enteramente burlesca marcada puntualmente por referentes graves. Mientras que en el otro extremo podemos situar el romance "A las fiestas vas, romance», constituido, además de un exordio (vv. 1-32) y de una conclusión (vv. 629-636), por una parte grave (vv. 33-308) y por una parte burlesca (vv. 309-628). En esta composición, el autor invoca a las dos musas de sendos estilos: a Clío, para el estilo grave y heroico, y a Talía, para el estilo burlesco. También invoca a la musa Melpómene para pedirle, ya que se trata de conmemorar la muerte del rey Carlos II de Inglaterra, que no haga sino una breve aparición para que el sentimiento fúnebre no enturbie el placer de las festividades celebradas en honor del nuevo monarca inglés Jacobo II Estuardo:

Préstenme sus abanicos

Clío y Talía, uno serio

y otro jovial, que hagan aire

muy cortesano y muy fresco.

Y si Melpómene infausta

tiene que llorar, sea luego,

porque no atropelle el gusto

la razón del sentimiento.

(OP, I, p. 308, vv. 25-32)

En los demás poemas - los más frecuentes - los estilos sublime y llano aparecen, como era de esperar, de manera imbricada. La mejor ilustración de esta diseminación efectiva es, sin duda, el romance «Gran señor, excelso duque», escrito en torno al año 1687 con motivo del nacimiento de Micaela Josefa de Portugal, hija del duque de Veragua, y de la recepción organizada para el evento.

El estilo simple y burlesco se puede observar en el empleo de un léxico y giros prosaicos y a veces vulgares ("ayunas", v. 43; "higas», v. 72; "ojeriza", v. 80; «norabuenas", v. 89; "parida", v. 112; "mantillas", v. 116; "salteador de caminos", v. 129), en el recurso tanto a la expresión popular "gastar higas» y al refrán «Mala noche y parir hija» (v. 61-64), como a la agudeza verbal (con la dilogía del sustantivo «vara»):

Y más en el gran Mendoza, en quien, para hacer lucidas las funciones de su vara, es su garbo su medida; (OP, I, p. 137, vv. 137-140)

Participan asimismo del estilo jocoso la tópica sátira contra los médicos («Pues la admiración gozosa / gastó en la recién nacida / y en su madre, bendiciones, / como en los médicos higas", vv. 69-72) así como la sufijación diminutiva en la palabra "norabuenita", indicadora de una connotación afectiva:

Y ésta que os doy, si yo viere

(o tentare) tan gran día, 
sea norabuena, que ahora no es más que norabuenita. (OP, I, p. 138, v. 181-184)

En cuanto a la escritura decorosa propia del panegírico, aparece en los campos léxicos de la alegría («enhorabuena», v. 3; «gozo», v. 6; «aplauso», v. 123; «aplausos», v. 162) y de la divinización ("sacro», v. 101; "adora", v. 102; "deidad», v. 103; «divinizar», v. 180), así como en el campo semántico de la nobleza y la majestad ("gran», v. 1; «excelso», v. 1; «excelsa», v. 53; «altas», v. 79; «imperial», v. 93; "corteja", v. 95; "soberana», v. 103; «heroica», v. 131, 160; «dignidad", v. 133; "gran", v. 137, 182; "lucidas", v. 138; "garbo", v. 140; "ínclito", v. 141; "anciana", v. 142; «nobleza», v. 143; «siempre ilustre», v. 145; «destreza», v. 153; «valor», v. 154; "gallardía", v. 154; "triunfos", v. 162; "grandeza", v. 169). Los adjetivos "tanto" (v. 21), "tantos" (v. 27) y el adverbio "tan" (v. 182), así como el sustantivo "concurso" (v. 119, uno de los cultismos léxicos característicos de la escritura de Góngora), pertenecen también a la escritura grave de la composición, como lo es la doble y triple adjetivación ( "No del sacro undoso Betis», v. 101; "la heroica / diestra Hermandad", vv. 131-132; "ha sido en mí esta encogida, / medrosa, desalentada / pereza de la osadía", vv. 17-20). Las metáforas ("aurora», v. 50; "alba», v. 51; "soles", v. 107) y los referentes mitológicos (Cintia, Diana, Lucina) entran asimismo en la elaboración del tópico de la divinización. En otra copla, podemos comprobar que el estilo elevado descansa en la doble adjetivación, el hipérbato, la personificación, el lugar común de la divinización así como la presencia de mitologemas:

No del sacro undoso Betis

adora la verde orilla

ninfa o deidad soberana

que no se humanase amiga.

(OP, I, p. 136, vv. 97-104)

Ahora bien, a pesar de la presencia nada secundaria de elementos de estilo elevado, hay que reconocer que, en la poesía jocoseria, lo que domina es el uso de los resortes cómicos de lo burlesco y, en particular, la degradación del estilo elevado. Sólo señalaremos dos ejemplos significativos.

En una copla sacada del romance «Invicto segundo Carlos», la degradación del lugar común de la divinización se produce mediante la introducción, al final del último verso, del sustantivo prosaico "pie» puesto en correlación con el sustantivo también prosaico «mano». Pese a la caracterización respectiva de los epítetos «soberano» y "real», la simetría de ambas palabras provoca una ruptura del estilo normalmente requerido para un elogio real:

Esto es, señor, que ya en tierra

el cielo del Norte, que es

gloria de vuestra real mano,

puso el soberano pie.

(OP, I, p. 68, v. 57-60) 
En la siguiente estrofa:

La inquietud del mar sus crespos

enmarañados mechones

sacude (no en plata riza

sino en mal peinado azogue).

(OP, I, p. 209, vv. 37-40),

la degradación estilística interna es multiforme. Notamos, primero, la asimilación metafórica de las olas con prosaicos "mechones" de cabello, el uso del sufijo aumentativo peyorativo -ón, la doble adjetivación -en el segundo caso peyorativadel sustantivo («crespos» y «enmarañados»). Observamos luego que el sustantivo culto "plata», metafóricamente el mar, queda calificado por el epíteto prosaico «riza», mientras la palabra "azogue», que significa metafóricamente la agitación, está caracterizada por el grupo adjetival «mal peinado», en el marco de una correlación establecida por la fórmula adversativo-aditiva $N o A, \operatorname{sino} B$.

\section{LA POESÍA EPIDICTICA J OCOSERIA: \\ UN EJEMPLO DE «ELOGIO DEL PRINCIPE"}

El romance «Invicto segundo Carlos» (OP, I, pp. 67-72), escrito para celebrar la feliz llegada a España, en 1690, de la segunda esposa de Carlos II, Mariana de Neoburgo se caracteriza, como en el romance "A las fiestas vas, romance», por su organización estilísticamente binaria. Se compone, además del exordio marcado por la captatio benevolentiae (vv. 1-40) y de la peroración (vv. 201-204), de un primer discurso descriptivo y burlesco (vv. 41-100), al que sigue un movimiento bisagra donde el yo lírico suspende el enunciado en una reflexión metapoética sobre el estilo que debe emplear (vv. 101-120) y, finalmente, un movimiento panegírico grave de la pareja real (vv. 121-200).

\section{Primer movimiento: laudatio burlesca}

El romance se presenta inicialmente como un texto epistolar donde, después de una apóstrofe al recién casado monarca español, aparecen cuatro topo $i$ relativos al "elogio del príncipe»: los de la invencibilidad del soberano («invicto»), de su amor hacia el pueblo («amante»), del amor del pueblo hacia su soberano ${ }^{15}$ ("amado») y de la sumisión del poeta panegirista:

\footnotetext{
1s Plinius Caecilius Secundus, Panegyricus Traiano, 21, 3: «itaque soli omnium contigit tibi, ut pater patriae esses, antequam fieres. Eras enim in animis, in iudiciis nostris, nec publicae pietatis intererat, quid vocarere, nisi quod ingrata sibi videbatur, si te imperatorem potius vocaret et Caesarem, cum patrem experiretur" ("Asi eres el único en haber sido el padre de la patria antes de convertirte en él. Lo eras en nuestros corazones, en nuestras almas, y la denominación en sí importaba poco a la piedad pública, pero se acusaba de ingrata al llamarte emperador y César cuando encontraba en ti un padre»); 22, 1: "Ac primum qui dies ille, quo exspectatus desideratusque urbem tuam ingressus es!" ("Y primero iqué día más hermoso aquel cuando, esperado, deseado, hiciste andando tu entrada en tu ciudad!»). Las traducciones son nuestras, como las siguientes de Plinio el Joven.
} 
Invicto segundo Carlos, amante y amado rey, que Dios guarde, como el mundo desea y ha menester; $(O P$, I, p. 67, vv. 1-4)

El procedimiento que permitirá al autor alcanzar su propósito jocoserio consiste en pasar el discurso epidíctico serio por el prisma paradójicamente convergente de lo burlesco. La parodia cómica nacerá de la yuxtaposición de los lugares comunes y procedimientos retóricos anquilosados y ampulosos del lenguaje epidíctico grave, por una parte, y, por otra, del prosaísmo procedente de la vida cotidiana. Tal es el caso de la parodia burlesca del lugar común de la modestia afectada, de la retórica humilitas, propia del exordio y perteneciente al tópico de la captatio benevolentiae ${ }^{16}$. Leamos los versos que siguen a la primera copla:

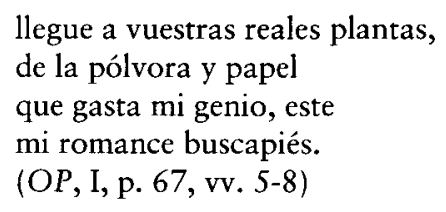

En ellos, a la expresiva imagen burlesca fundada en la dilogía del sustantivo compuesto «buscapiés» y la consiguiente asimilación entre el acto de humildad y sumisión y el petardo que sigue obstinadamente los pasos de los huyentes —al que está metafóricamente comparada la composición - se añade la correlación cómica que une la dignidad de las «reales plantas» de Carlos II a los pies vulgares que forma el citado sustantivo.

De igual modo, la dulce cítara, instrumento lírico por excelencia, no corresponde con la inspiración a ras del suelo del poeta:

No a la cítara le canto,
sino a un intrumento fiel,
que en saberle destemplar
está el primor del tañer.
Para formar la alegría
sus consonancias, tal vez
suele buscar un clarín
y da con un cascabel.
$(O P, I$, p. 67, vv. $9-16)$

Lo jocoserio, en el marco de la poesía epidíctica de José Pérez de Montoro, consiste, pues, en rebajar sistemáticamente todos los lugares comunes con parodias burlescas muchas veces in praesentia. Cada elemento grave encuentra inmediatamente su contrapunto degradante: al verbo «tañer» y al sustantivo «clarín» les corresponden

\footnotetext{
${ }^{16}$ Cicéron, De l'invention, I, 16, 22: «prece et obsecratione humili ac supplici utemur».
} 
respectivamente el verbo "destemplar" y el sustantivo "cascabel", puesto cada binomio en correlación en un paralelismo sintáctico final.

Según Menandro el Rétor ${ }^{17}$, la demostración de alegría es fundamental en todo discurso de llegada. Pues bien, dicha demostración, en nuestro poema, combina prosaísmo, oralidad ( ¡iAleluya!», a la vez marcador de oralidad e irrupción del discurso directo) y antítesis estilística:

$$
\begin{aligned}
& \text { Cuando estaba la tristeza } \\
& \text { desesperada en hacer } \\
& \text { de cada día un puñal } \\
& \text { y de cada hora un cordel, } \\
& \text { «iAleluya!», dijo el cura; } \\
& \text { y Dios, viendo nuestra fe, } \\
& \text { su copiosa redención } \\
& \text { nos hizo la gran merced. } \\
& \text { (OP, I, p. } 68, \text { vv. } 45-52 \text { ) }
\end{aligned}
$$

Y los procedimientos cómicos se prolongan en la descripción de la llegada de la soberana:

\author{
Dionos, en fin, la noticia \\ de aquel gran consuelo, aquel \\ que ha tenido el respirar \\ pendiente del suceder. \\ Esto es, señor, que ya en tierra \\ el cielo del Norte, que es \\ gloria de vuestra real mano, \\ puso el soberano pie. \\ (OP, I, p. 68, vv. 53-60)
}

El estilo elevado, en estos versos, de acuerdo con el propósito laudatorio de la obra, se encamina progresivamente hacia la ruptura del decoro. Al énfasis nacido de la presencia del demostrativo - repetido y subrayado por el encabalgamiento del verso 54-, de la caracterización adjetival enfática ("gran», "real", "soberano»), de la alusión metafórica hiperbólica a la reina Mariana de Neoburgo ("el cielo del Norte») ${ }^{18}$ y del sustantivo "gloria" se opone de repente la comicidad de los versos 59-60 provocada por la yuxtaposición voluntaria, que ya comentamos, de la real mano del monarca y del pie que la reina acaba de posar en el suelo español.

Esta primera descripción presenta algunas características formales que le confieren cierta autonomía en el conjunto de la composición. Empieza con una suerte de exordio donde el autor manifiesta tanto alegría como humildad, subrayando su incapacidad para cantar la entrada real por su «ronca estolidez». Por otra parte, la alegría del poeta ante

${ }^{17}$ Menandro el Rétor, Dos tratados de retórica epidictica, II, 378, 3-4; 382, 1-3; 385, 8.

${ }^{18}$ Comparaciones y metáforas son inherentes al discurso laudatorio. Plinio el Joven, al meditar sobre el elogio, ya había afirmado en su Panegírico de Trajano, que "no [había] buen elogio sin comparaciones» (Plinius Caecilius Secundus, Panegyricus Traiano, 53, 1-2: «alioqui nihil non parum grate sine comparatione laudatur»). 
el tan esperado acontecimiento se manifiesta de manera cómica con la introducción de la interjección familiar "¡Válgame Dios!" y del sustantivo "estolidez", sustantivo escogido por sus sonoridades tan discordantes como las del epíteto "ronca" que le caracteriza:

¡Válgame Dios, y qué asunto!

¡Si mi ronca estolidez

cantar supiera, o rezar

lo que se puede ofrecer!

$(O P, \mathrm{I}$, p. 68, vv. 61-64)

El tópico de la humilitas está maltratado, como lo será también, a partir de los versos siguientes, el de la divinización, ese procedimiento común —insistentemente manejado por el poeta en su evocación de viaje marítimo de la reina- que consiste en atribuir a la persona homenajeada un carácter divino, pagano o religioso, sea por comparación metafórica, sea por su pertenencia a un entorno divino.

La vena burlesca del autor se explaya en la presentación del navío de la reina Mariana de Neoburgo. Su estilo podría parecer elevado si sólo nos fijásemos en la doble adjetivación del primer verso ("náutica real») y en el lenguaje metafórico culto empleado por el autor - la metáfora lexicalizada "cerúlea tez» en lugar de mar-, pero la introducción del verbo prosaico y disonante "desarrugar» para pintar la evolución rápida del barco ridiculiza los términos y procedimientos encomiásticos difundidos en la copla:

¡La náutica real carroza, con qué aire no se ha de ver desarrugando veloz del mar la cerúlea tez! $(O P$, I, p. 69, vv. 73-76)

Asistimos asimismo, en un caso ejemplar de degradación estilística interna, a una degradación del topos de la divinización, tan presente en los panegíricos antiguos ${ }^{19}$. Los cisnes que tiran de la concha gigante que sirve de embarcación a Venus - llamada «plaustro de nácar» para referirse metafóricamente a la embarcación de la hija de Ouranos e, in absentia, al navío de la reina, asimilada a la diosa Venus por alusión perifrástica ("la madre de Amor») - son asimilados a meras bestias de carga tirando de un carruaje:

¡Qué no entonarán los cisnes

desuncidos del primer

plaustro de nácar, de que hizo

la madre de Amor bajel!

(OP, I, p. 68, vv. 65-68)

\footnotetext{
${ }^{19}$ Como por ejemplo en el Panegírico de Trajano: «¿Qué obsequio del cielo es más valioso o más hermoso que un emperador virtuoso, santo y muy parecido a los dioses?" (Plinius Caecilius Secundus, Panegyricus Traiano, 1, 3: "quod enim praestabilius est aut pulchrius munus deorum quam castus et sanctus et dis simillimus princeps?»).
} 
Parecidamente, Pérez de Montoro trata de manera burlesca el discurso epidíctico en su descripción enfática del buque de la reina, una nave cargada de hipérboles y descrita con los dos procedimientos hiperbólicos que son el recurso al adverbio superlativo «más» y la inserción del complemento circunstancial de lugar con valor asimismo superlativo:

\author{
$\mathrm{Y}$, en fin, la nao conductora, \\ ¡cuál vendrá a más no poder \\ de hipérboles que la carguen, \\ desde el timón al bauprés! \\ (OP, I, p. 69, vv. 97-100)
}

La caracterización de Tetis y de Neptuno, en la copla siguiente, hunde de nuevo al lector en la comicidad burlesca, gracias a la calificación adjetival y a las aliteraciones:

\author{
¡Tetis, deidad zambullida, \\ cuál no andará sobre hacer \\ que enjugue el sol de Neptuno \\ la remojada vejez! \\ (OP, I, p. 69, vv. 81-84)
}

La más famosa de las nereidas y el dios del Océano van respectivamente caracterizados con el participio pasado «zambullida", que se opone, por sus mediocres sonoridades, al sustantivo con el que concuerda, "deidad»; y con el participio pasado "remojada", que, junto con el sustantivo "vejez», realza la figura ridícula del dios pagano. Las aliteraciones en $/ \mathbf{j} / \mathrm{y}$ en $/ \theta /$ subvierten por sus sonoridades los mitologemas y se oponen por ello a la elaboración de un estilo grave que se conformaría más con el género epidíctico.

Más adelante, Pérez de Montoro juega con los verbos «transplantar»y «crecer» para degradar a los monstruos Caribdis y Escila:

¿Qué no asustarán Caribdis

y Scila, pues hubo quien

las transplantó en aquel mar, juzgando que han de crecer!

(OP, I, p. 69, vv. 89-92),

monstruos que, para las necesidades del discurso encomiástico, van arrancados de su lugar de origen - el estrecho de Mesina, donde vivían de un lado y otro-, para ser replantados, como si de vulgares plantas se tratara, en la ruta del cortejo real para subrayar hiperbólicamente los peligros de la travesía marítima

\title{
Segundo movimiento: reflexión metapoética sobre la poesía epidíctica
}

Así se termina el movimiento descriptivo laudatorio, ritmado por la acumulación de referentes mitológicos, por la sucesión de enunciados exclamativos y por la anáfora compleja formada por el pronombre interrogativo "qué" seguido de la negación "no" 
(vv. 65, 69, 89 y 93). Se interrumpe bruscamente en un verso estrictamente binario para dejar lugar a una verdadera reflexión metaliteraria por parte del yo lírico. Por mucho que el yo lírico haya procedido a la subversión del discurso epidíctico serio, su texto no dejó de pertenecer, a su entender, al estilo elevado y ampuloso. Frente a la opacidad de este género de discurso, el enunciador poético se subleva con un «no» categórico, que marca la cesura de verso 101, y propugna el uso de un lenguaje claro en un enunciado imperativo breve. La oposición entre un lenguaje que el yo lírico considera lleno de mentiras y que afirma ser incapaz de adoptar, y el de la claridad reivindicada queda subrayada en la antítesis "no sé»/ «sé», acentuada por el encabalgamiento del verso 102:

$$
\begin{aligned}
& \text { Pues eso no; vamos claros: } \\
& \text { yo no sé mentir, y sé } \\
& \text { que el mar toda es pura sal, } \\
& \text { con que no he de hacerle miel. } \\
& \text { (OP, I, p. 69, vv. 101-104) }
\end{aligned}
$$

En la copla siguiente, la dilogía del verbo «moler» subraya la necesidad de cierta mesura en la hinchazón del discurso epidíctico. Puesto que el número de colores es proporcional al tamaño del cuadro, cuanto mayor sea éste, cuanto más se expone el pintor al riesgo de deber moler más ingredientes para obtener sus colores, y al riesgo de "moler" ("molestar gravemente y con impertinencia", Autoridades) al destinatario de su elogio:

No me acomodo a endulzarle con mis tintas, que el pincel, que gasta mucho color, se expone a mucho moler. (OP, I, p. 69, vv. 105-108)

De ahí que el poeta se proponga hacer un elogio escrito según las leyes del género jocoserio, cuya comicidad descansará en un desfase, en un contraste entre la intención laudatoria del yo lírico y la vulgaridad y el prosaísmo de su expresión. Anuncia así que alabará a la nueva esposa de Carlos II - a la que alude mediante una perífrasis ("al primor / con que se dejó vencer») - con los pies secos y «a cien leguas» de donde se encuentra. Parecidamente, pintará la devoción amorosa del rey valiéndose de una agudeza creada a partir de la deslexicalización de la expresión figurada y familiar "poner pies en pared» ${ }^{20}$ y de su correlación por yuxtaposición con el sustantivo «brazos» $\mathrm{y}$ «pies»:

A pie enjuto y a cien leguas

de su orilla, ya le haré

algún encomio al primor

con que se dejó vencer;

\footnotetext{
${ }^{20}$ «Frase que vale determinarse a ejecutar alguna cosa, firmemente y con resolución, sin embarazarse en las dificultades y riesgos que pueden resultar de su ejecución» $(A u t$.
} 
aunque de todo es indigno

quien se detuvo en ceder

sus brazos a una deidad,

poniendo pies en pared.

(OP, I, p. 69-70, vv. 109-116)

Tercer movimiento: laudatio grave

Contra todo pronóstico y al contrario de lo que podía dejar suponer el estilo empleado hasta ahora por el autor, el texto panegírico burlesco deja lugar, a partir del verso 121 , a un texto panegírico de lo más serio. Este panegírico grave empieza con la presentación de la nueva reina de España por medio de alusiones metafóricas cósmicas. La llegada y la belleza de Mariana de Neoburgo hacen que el autor la compare con el Alba y la Aurora, trilladas personificaciones heredadas del lenguaje amoroso petrarquista ${ }^{21}$. Así el levantar o la llegada de la dama se parece al del día; la palidez de su piel, a la blancura inmaculada del alba («candor»); y los colores de su rostro, a los de la aurora («rosicler») ${ }^{22}$. En cuanto al sol, representa, con sus rayos, los ojos de la dama. A través de su suave sonrisa, los rayos del sol matutino consiguen atenuar la sed ardiente de amor:

\author{
¿Quién viene allá? Viene el Alba; \\ claro está, pues ya se ve. \\ ¡Oh, quién supiera gastar \\ el candor y rosicler! \\ ¿No es la Aurora, en cuya sola \\ dulce risa ha de poder \\ templar el sol de sus rayos \\ la ardiente amorosa sed? \\ (OP, I, p. 70, pp. 121-128)
}

Más adelante aparece el convencional tópico de la divinización. El interés de la estrofa radica en la aproximación ingeniosa entre la esfera divina del rey y de su esposa, por una parte, y la esfera humana, por otra. La divinización del rey es realizada

\footnotetext{
${ }^{21}$ Manero Sorolla, 1990, pp. 495-510.

${ }^{2}$ La comparación del príncipe con los elementos cósmicos, más que frecuentes en la literatura de elogio, tiene antecedentes, en lo que concierne al discurso de recepción o de entrada de príncipe, en los discursos de llegada de gobernadores, tales como los presentaba Menandro el Rétor cuando le pedía al orador que manifestara en su epílogo el entusiasmo del pueblo al llamar al gobernador "estrella más luminosa» o «luz del sol más luminosa" (Menandro el Rétor, Dos tratados de retórica epidíctica, II, 381, 12-13 y 17). Podemos también señalar el empleo, en el panegírico que Plinio el Joven le dedica a Trajano, de la comparación con el sol con el fin de ilustrar la difusión de las luces intelectuales del emperador a sus súbditos: "Pero los tienes todos [los hallazgos de sus reflexiones] difundidos a la vez, como el sol y el día lucen no por fragmentos, sino de golpe todo enteros, no para tal o tal, sino para todos los hombres en común» (Plinius Caecilius Secundus, Panegyricus Traiano, 35, 5: «at tu simul omnia profudisti, ut sol et dies non parte aliqua, sed statim totus, nec uni aut alteri, sed omnibus in commune profertur»). Y antes lo había comparado con las estrellas: "Tal es la naturaleza de las constelaciones que las pequeñas y las débiles son oscurecidas por el despertar de las más fuertes. Así la llegada del emperador eclipsa el prestigio de sus legados» (Plinius Caecilius Secundus, Panegyricus Traiano, 19,1: «Est haec natura sideribus, ut parva et exilia validiorum exortus obscuret; similiter imperatoris adventu legatorum dignitas inumbratur»).
} 
mediante un silogismo elíptico simple: el rey toma por esposa a una deidad, entonces el rey es un dios. Sin embargo, el rey participa también de la naturaleza humana al tomar por esposa a la «mujer» Mariana de Neoburgo:

¿No es, señor, la real esposa,

la augusta Mariana, a quien

todos adoran deidad

y vos aguardáis mujer?

(OP, I, p. 70, vv. 133-136)

Mariana, que ya tenía la imprescindible belleza corpórea que Curtius señalaba como una de las cuatro cualidades naturales en todo discurso epidíctico ${ }^{23}$, es ahora divinidad adorada por todos, otro lugar común definido por Curtius como "todos cantan su alabanza" o "todo el orbe canta su alabanza" ${ }^{4}$.

A continuación, el proceso de divinización de la joven austriaca se traduce en una serie de tres metáforas, de tres amplificaciones por comparación. Mariana de Neoburgo es comparada respectivamente con las diosas romanas Diana, Venus y Juno:

Pues venga y viva el asombro

de la hermosura y desdén

que es Diana y Venus ahora,

para ser Juno después.

(OP, I, p. 70, vv. 137-140)

El autor quiere subrayar, en un primer tiempo, la belleza y la castidad de la joven esposa representadas respectivamente por Venus, diosa del amor, y Diana, que preservaba ferozmente su virginidad menospreciando a sus pretendientes. "Hermosura" y «desdén» son, pues, las virtudes de la joven esposa, cuya correspondencia con su personificación mitológica se efectúa mediante un quiasmo en los versos 138 y 139. En cambio, la comparación de Mariana de Neoburgo con la diosa Juno, encarnación del matrimonio y la maternidad, y diosa protectora de las mujeres embarazadas y de los recién nacidos, remite a la espinosa y preocupante cuestión de la sucesión del rey, a la que el autor había aludido algunos años antes en una loa palatina dedicada a la primera esposa del monarca español, María Luisa de Orleáns ${ }^{25}$.

Además de la amplificación por comparación, el autor recurre al lugar común de "sobrepujamiento" 26 en su representación hiperbólica de la segunda esposa de Carlos II, que reúne en sí las virtudes de las tres Gracias romanas:

${ }^{23}$ Curtius, 1956 , pp. 260-262.

${ }^{24}$ Curtius, 1926, p. 233.

${ }^{25}$ Véase $O P$, I, pp. 406-407, vv. 539-552: «Y vos, soberana Juno, / -pero no explique profana I fecundidad tan augusta / madre y reina, pues más altas / divinas glorias promete / el gran nombre de Mariana-/ vivid, y vuestras virtudes, / de vuestros nombres se valgan / para que el Cielo responda / a la gran voz que le llama, / pues no es dudable que el mismo / que os permitió que gozarais / para madre el de María, / os dio para abuela el de Ana".

${ }^{26}$ Curtius, 1956, pp. 235-239. 


\author{
Venga y viva la que tanto \\ abulta las gracias que \\ montan en su perfección \\ por más de tres mil las tres. \\ (OP, I, p. 70-71, vv. 149-152)
}

Cabe subrayar, sin embargo, que, pese al propósito estrictamente laudatorio de Pérez de Montoro, su escritura no deja de reflejar cierto prosaísmo que, por otra parte, y como ya señalamos en otra ocasión, es característica de la escritura de la época de los novatores ${ }^{27}$. Así, en la copla que acabamos de citar, la superación de los modelos mitológicos se expresa a través de una prosaica comparación matemática.

Estos distintos lugares comunes destinados a conferirle a la nueva reina una belleza, una perfección y un estatuto divinos dan paso luego a otros tópicos tradicionales relativos, éstos, a la descendencia, y a la inmortalidad del soberano ${ }^{28}$. El primero de ellos, el de la descendencia, aparece en dos coplas. En la primera, el yo lírico se hace eco de la general preocupación de los españoles por la falta de sucesores de su monarca y exhorta a la reina a que le dé muchos hijos, utilizando metáforas sacadas de mundo vegetal y del juego. El discurso hiperbólico se apoya, para la representación convencional de la descendencia, en el tópico de la multiplicación de hojas o de frutos del laurel o del olivo, símbolos respectivos de la victoria y de la sabiduría, y en una comparación metafórica original y prosaica entre los hipotéticos palacios de los futuros príncipes y las casillas del ajedrez:

\author{
Venga y viva, dando tantas \\ hojas al sacro laurel, \\ que conste de más palacios \\ que casas el aljedrez. \\ (OP, I, p. 71, vv. 153-156)
}

Mientras que la segunda copla, en la que se refleja la preocupación sucesoria, se inspira en referentes bíblicos, hecho bastante raro en la poesía epidíctica destinada a seculares. En una enésima hipérbole, el poeta pide a la reina que dé nacimiento a gemelos que lucharán por nacer antes el uno que el otro y convertirse así uno de los dos en sucesor del soberano español. Pérez de Montoro echa mano aquí del episodio bíblico de Farés y Zará, hijos de Judá y Tamar ${ }^{29}$, para significar a la vez la descendencia real,

\footnotetext{
${ }^{z}$ Bègue, 2008, en prensa.

${ }^{28} \mathrm{El}$ autor de la Retórica a Herennio (Rhétorique à Herennius, II, 48) y Cicerón, en su De inventione (Cicéron, De l'invention, I, 100-101), lo propugnaban ya en sendos escritos. Los oradores tenían asimismo que referirse a los lugares comunes del nacimiento ilustre (R hétorique à Herennius, III, $10 \mathrm{y}$ 13; Cicéron, De l'invention, I, 34-36 y II, 177; Quintilien, Institution oratoire, III, 7, 10; Menandro el Rétor, Dos tratados de retórica epidíctica, II, 370, 28-371, 14.) y la vida ilustres del individuo homenajeado, el de la nobleza de la ascendencia (Rhétorique à Herennius, III, 10; Cicéron, De l'invention, II, 177; Quintilien, Institution oratoire, III, 7, 10), o también los de la sabiduría y la amabilidad (en lo que respecta al elogio del carácter, véase Quintilien, Institution oratoire, III, 7, 15).

${ }^{29} \mathrm{Gn} 38,27-30$ : «Y aconteció que al tiempo de dar a luz, he aquí había dos en su vientre. Y sucedió, cuando dio a luz, que sacó la mano el uno, y la partera tomó y ató a su mano un hilo de grana, diciendo: Este salió primero. Y aconteció que tornando él a meter la mano, he aquí su hermano salió; y ella dijo: ¿Por qué
} 
simbolizada por el hilo de color púrpura que llevaba Zará en la muñeca, la sucesión fecunda, mediante el nacimiento doble, y la rapidez del nacimiento deseado, mediante la lucha fratricida por salir primero:

\author{
Venga y viva, y haya infantes \\ Gemelos, que por nacer \\ al listón purpúreo lidien \\ como Zarán y Farés. \\ $(O P$, I, p. 71)
}

El último movimiento interno de la laudatio grave, introducido con la ruptura de la anáfora compleja "venga y viva» que iba ritmando las coplas precedentes, se dirige al dedicatario del elogio, el rey Carlos II. El concepto por ponderación misteriosa de las dos primeras estrofas se funda en la llegada de Mariana de Neoburgo - alba y aurora y, pues, sol- y confiere al monarca una esencia divina, ya que le otorga el poder de alterar el orden del día:

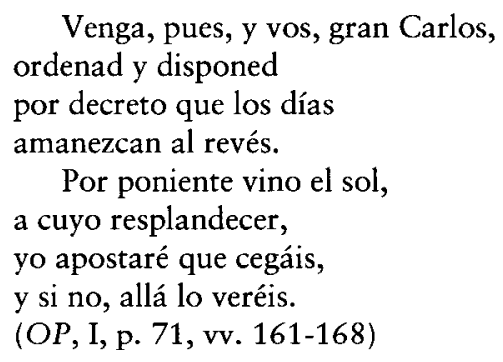

A continuación, aludiendo una vez más a la cuestión sucesoria, el poeta le anima a que se reúna cuanto antes con su esposa ("con tres luegos»), sin esperar siquiera a que el sumiller de corps le vista, para que ambos vuelvan a la Corte después de haberse unido en vista de la concepción de un sucesor. Punto, este último, hábilmente presentado en una perífrasis alusiva en la que el poeta subraya el beneficio que tal unión tendría sobre el apaciguamiento de los temores de los súbditos reales:

\footnotetext{
Ea, señor, a la dicha que os busca, pues ya sabéis, cuanto al aire de esperar, se habrá encendido el querer.$$
\text { Ea, señor, al camino, }
$$
madrugad y no aguardéis para que os den de vestir a que venga el sumiller.
}

has hecho sobre ti rotura? Y llamó su nombre Fares. Y después salió su hermano, el que tenía en su mano el hilo de grana, y llamó su nombre Zara» («instante autem partu, apparuerunt gemini in utero: atque in ipsa effusione infantum unus protulit manum, in qua obsetrix ligavit coccinum dicens: iste egreditur prior. illo vero retrahente manum, egressus est alter: dixitque mulier: quare divisa est propter te maceria? et ob hanc causam, vocavit nomen eius Phares. postea egressus est frater, in cuius manu erat coccinum: quem appellavit Zara"). 
Id por vuestra amada esposa, y allá entre los dos volved con algo que sospechar que nos quite el que temer.

Despachaos vos a vos mismo con tres luegos, y corred, pues son los plazos de amor partir, llegar y volver. (OP, I, p. 71, vv. 173-188)

Pero aquí también, y como señalamos, Pérez de Montoro no puede menos de emplear, en el seno mismo de su laudatio grave, unos elementos propios del estilo llano. Así el uso del léxico notarial con el que comienza la última de las coplas citadas («Despachaos», v. 185; «luegos», v. 186). Y es que, como subrayó Ignacio Arellano, «el barroco español opta por la integración de niveles, registros y jergas varias", añadiendo que «[l]as lenguas técnicas se admiten plenamente como material literario, favorecidas por el desarrollo del lenguaje figurado ${ }^{30}$. Heredero de una práctica literaria que se remonta a principios del siglo xviı, Pérez de Montoro la recoge en su obra, pero trivializándola.

El cierre del discurso panegírico serio se efectúa por medio de los tópicos convencionales del amor del pueblo para con su soberano y de la inmortalidad de este último:

$\quad$ Id a que vuestros vasallos
os vean venir, porque
la ternura de los ojos
tenga sobre qué llover.
$(O P, \mathrm{I}, \mathrm{pp} .71-72)$

La hipérbole, aquí, reside en la personificación de la "ternura» y la alusión hiperbólica a los sollozos en la comparación metafórica entre lágrimas y lluvia ( «llover»).

Por su parte, el tópico de la deseable longevidad del monarca se ofrece de manera superlativa en unos versos en los que el poeta pide a Carlos II que viva tantos años como para que Adán y Matusalén, símbolos bíblicos de longevidad, parezcan niños a su lado. El topos de "sobrepujamiento" está realzado con la simetría sintáctica casi perfecta de los versos 195-196 en que se inscriben los dos referentes bíblicos:

\footnotetext{
Id, y vivid tantos años

que con vos, al fallecer, parezca un muchacho Adán, y un rapaz Matusalén.$$
(O P, \mathrm{I}, \mathrm{p} .72)
$$

El romance jocoserio concluye con una convencional manifestación de humildad por parte del yo lírico. El tópico de la humilitas aparece sin embargo de manera cómica,

\footnotetext{
${ }^{30}$ Arellano, 2003, p. 196.
} 
como podíamos esperar, en la petición hecha al soberano de no tratar de averiguar la identidad del autor de las numerosas extravagancias contenidas en la composición - por supuesto Pérez de Montoro debía de desear todo lo contrario-, pues el individuo en cuestión carece de interés:

\author{
Y si desatinos tantos \\ perdonáis, no preguntéis \\ qué hombre es éste, porque este hombre \\ es menos que el si es no es. \\ (OP, I, p. 72)
}

La aliteración en /s/ y /e/, sobre todo mediante la repetición de la sílaba "es", sea a través del verbo ser en tercera persona del presente del indicativo, sea por su presencia en algunas palabras («desatinos», «éste», «este») acentúan el propósito cómico de la conclusión.

La progresiva difuminación de las fronteras impuestas por el decoro estilístico llega, en la segunda mitad del siglo xviI, a extremos insospechados. El estilo jocoserio, que algunos, como el conde de Clavijo, quisieron criticar, se extendió por todo el espectro poético. Y es que sólo contaba el placer y la risa del dedicatorio y/o del auditorio, una risa que el poeta, que reviste en el caso de la poesía epidíctica la máscara del bufón, debe absolutamente producir para presentarse como cortesano o contar con las dádivas de su superior jerárquico. En el caso de José Pérez de Montoro, el “deleitar” era la esencia misma de unas obras laudatorias producidas en un contexto eufórico que justificaba de esta manera la ruptura del decoro estilístico. Esta ruptura, esta invasión del conceptismo burlesco, esta mezcla del movere y del delectare hacen de la escritura jocoseria, y en especial de su vertiente laudatoria, una escritura emblemática de la literatura de finales del siglo xvir, a la par que muestra hasta qué punto la expresión de la agudeza verbal y sus manifestaciones "vulgares y bajas" no se habían limitado, en aquel entonces, a una «infraliteratura ${ }^{31}$, sino que, por el contrario, constituían uno de los fundamentos de la escritura poética ultrabarroca, y un grado último del conceptismo. Dentro de este panorama, José Pérez de Montoro fue un notable portavoz de esta modalidad literaria, y su capacidad para producir la comicidad explotando todos los resortes posibles de la agudeza le aseguró — por lo menos durante algunas décadas - el paso a la posteridad literaria ${ }^{32}$.

${ }^{31}$ Chevalier, 1992, p. 250.

${ }^{32}$ Así lo demuestran la aprobación a la obra de José Tafalla Negrete hecha por Pedro Miguel de Samper, cronista del reino de Aragón, a principios del siglo xviII (véase Bègue, 2006, p. 153) así como los más de setenta manuscritos que recogen poemas de nuestro poeta setabense (casi veinte de ellos dedicados integramente a su obra). 
Referencias bibliográficas

Arellano, Ignacio, Poesía satírico-burlesca de Quevedo Madrid/Frankfurt am Main, Iberoamericana/Vervuert (Biblioteca Áurea Hispánica, 15), 2003.

Bègue, Alain, Recherches sur la fin du Siècle d'or espagnol: José Pérez de Montoro (1627-1694), Toulouse, Université de Toulouse-Le Mirail, 2004. Tesis doctoral.

— - "Aproximación a la lengua poética de la segunda mitad del siglo xvir: el ejemplo de José Pérez de Montoro", en Investigaciones recientes sobre la literatura del Siglo de Oro. Homenaje a Julián Durán. Seminario de la Casa de Velázquez (Madrid, 3 y 4 de mayo de 2004), eds. Alain Bègue, Agnès Delage y Christel Lapisse, Criticón, 97-98, 2006, pp. 153-170.

- - "Aspectos estilísticos de la escritura poética de finales del siglo Xviı", en La literatura española en tiempos de los novatores (1675-1726), eds. Alain Bègue y Jean Croizat-Viallet, Criticón, 2008, en prensa.

Chevalier, Maxime, Quevedo y su tiempo: la agudeza verbal, Barcelona, Crítica (Filología, 24), 1992.

Cicéron, De l'invention, ed. Guy Achard, Paris, Les Belles Lettres (CUF. Série Latine, 320), 2002.

Curtius, Ernst Robert, Literatura europea y Edad Media latina, trad. Margit Frenk Alatorre y Antonio Alatorre, México, Fondo de Cultura Económica (Lengua y Estudios Literarios), 1955.

Egido, Aurora, Fronteras de la poesía en el barroco, Barcelona, Crítica (Filología, 20), 1990.

Étienvre, Jean-Pierre, «Primores de lo jocoserio», Bulletin Hispanique, 1, 2004, pp. 235-252.

Jauralde Pou, Pablo (ed.), Antología de la poesía española del Siglo de Oro (Siglos XVI-XVII), apéndice de Mercedes Sánchez Sánchez, Madrid, Espasa-Calpe (Austral, 472), 1999.

Manero Sorolla, María Pilar, Imágenes petrarquistas en la lírica española del Renacimiento. Repertorio, Barcelona, PPU (Estudios de literatura española y comparada, 7. Serie maior), 1990.

Menandro el Rétor, Dos tratados de retórica epidíctica, eds. Fernando Gascó, Manuel García García y Joaquín Gutiérrez Calderón, Madrid, Gredos (Biblioteca Clásica Gredos, 225), 1996.

Pérez de Montoro, José, Obras posthumas lyricas..., Madrid, Antonio Marín, 1736, 2 tomos.

Platon, Euvres complètes. Tome IV. $3^{e}$ partie: Phèdre, eds. Léon Robin, Claudio Moreschini y Paul Vicaire, Paris, Les Belles Lettres (CUF. Série grecque, 302), 2002.

Plinius Caecilius Secundus, Gaius, Panegyricus Traiano, en C. Plini Caecili Secundi Epistularum libri novem / C. Plini Caecili Secundi Epistularum ad Traianum liber, ed. Mauritius Schuster, Stutgardiae/Lipsiae, Teubner (Bibliotheca scriptorum Graecorum et Romanorum Teubneriana), 1992, pp. 367-455.

Quintilien, Institution oratoire, ed. Jean Cousin, Paris, Les Belles Lettres (CUF. Série latine, 216, 223-225, 237, 239 y 249), 2003, 7 tomos.

QuiÑones De BenAVEnTE, Luis, Entremeses completos I. Jocoseria, eds. Ignacio Arellano, Juan Manuel Escudero y Abraham Madroñal, Madrid/Frankfurt am Main, Iberoamericana/ Vervuert (Biblioteca Áurea Hispánica, 14), 2001.

Rhétorique à Herennius, ed. Guy Achard, Paris, Les Belles Lettres (CUF. Série Latine, 287), 2003.

Tafalla y Negrete, José, Ramillete poético..., Zaragoza, Manuel Román, 1706. 
BÈGUE, Alain. «Los límites de la escritura epidíctica: la poesía jocoseria de José Pérez de Montoro». En Criticón (Toulouse), 100, 2007, pp. 143-166.

Resumen. Mediante el estudio de la poesía epidíctica de José Pérez de Montoro, este artículo pretende mostrar hasta qué punto el estilo jocoserio logró alcanzar los géneros literarios más nobles y convertirse así en una tendencia característica y representativa de la escritura literaria de finales del siglo xviI.

Résumé. À travers l'étude de la poésie épidictique de José Pérez de Montoro, cet article prétend montrer à quel point le style jocoserio parvint à atteindre les genres littéraires les plus nobles et devint ainsi une tendance caractéristique et représentative de l'écriture littéraire de la fin du XVIr siècle.

Summary. Through the study of José Pérez de Montoro's epidictic poetry, this article aims to show how the jocoserious style reached the most noble literary genres and became a characteristical and representative tendency of the literary writing of the end of the seventeenth century.

Palabras clave. Jocoserio. Pérez de Montoro, José. Poesía epidíctica. Poesía jocoseria. Poesía laudatoria. 